Águas Subterrâneas (2012) 26(1): 19-26.

\title{
MONITORAMENTO DA ATENUAÇÃO NATURAL DE ÁLCOOL ETÍLICO HIDRATADO COMBUSTÍVEL EM ESCALA LABORATORIAL POR MEIO DE MÉTODOS GEOFÍSICOS
}

\author{
NATURAL ATTENUATION MONITORING OF THE ETHYL ALCOHOL \\ HYDRATED COMBUSTIBLE IN LABORATORIAL SCALE FOR \\ GEOPHYSICAL METHODS
}

\author{
Antonio Celso Oliveira Braga ${ }^{1}$, Cesar Augusto Moreira ${ }^{1}$
}

Artigo recebido em: 16/02/2012 e aceito para publicação em: 24/04/2012

\begin{abstract}
Currently has few studies today concerning the behavior of the ethyl alcohol hydrated combustible in the geological environment, results of eventual spill or leaks in a wide transport chain and distribution. This work discusses the results of an experiment in laboratorial scale, that involves the monitoring of alterations in physical properties a simulate leak of alcohol in a tank with sand saturated in water, during 4920 hours. Are applied electrical resistivity, induced polarization and spontaneous potential geophysical methods. The electric resistivity is clearly correlating to the ethanol degradation pattern. The chargeability demonstrated sensibility to this pattern, while the natural electric potential revealed direct association with the oscillations of groundwater level. The variability of the physical parameters monitoring probable control for ethanol degradation process in environment study.
\end{abstract}

Keywords: Electrical profiling. Aerobic. Oxidation. Applied geophysics.

Resumo: Atualmente existem poucos estudos acerca do comportamento do álcool etílico hidratado combustível no ambiente geológico, fruto de eventuais derrames ou vazamentos numa ampla cadeia de transporte e distribuição. Este trabalho discute os resultados de um experimento em escala laboratorial, que envolve o monitoramento de alterações em propriedades físicas de um vazamento simulado de álcool, num tanque com areia parcialmente saturada em água, durante 4920 horas. Foram utilizados os métodos geofísicos de eletrorresistividade, polarização induzida e potencial espontâneo. A resistividade elétrica foi claramente correlacionável ao padrão de degradação do etanol. A cargabilidade demonstrou sensibilidade a este padrão, enquanto que o potencial elétrico natural revelou associação direta com as oscilações do nível freático. A variabilidade dos parâmetros físicos monitorados foi possivelmente controlada por processos de degradação do etanol no ambiente estudado.

Palavras-chave: Perfilagem elétrica. Aeróbico. Oxidação. Geofísica aplicada.

\section{INTRODUÇÃO}

Uma das fontes preocupantes de contaminação dos materiais geológicos e das águas subterrâneas são vazamentos de combustíveis a partir de postos de abastecimento, refinarias, oleodutos, dentre outros. O processo de atenuação natural compreende uma variedade de processos físicos, químicos e biológicos de ocorrência natural no ambiente, que dentro de condições favoráveis permitem a redução de massa, toxicidade, mobilidade, volume ou concentrações de contaminantes no solo ou água subterrânea sem intervenção humana (EPA, 1999).

Este processo ocorre naturalmente em qualquer área contaminada, com variável grau de eficiência, dependendo dos tipos e concentrações de contaminantes presentes e dos processos físicos, químicos e biológicos característicos do solo e da água subterrânea, com capacidade de redução dos riscos potencialmente associados a estas áreas.

Existem diversos procedimentos de monitoramento de áreas sob atenuação natural, como análises químicas em amostras de águas subterrâneas e solo, medições de gás no solo, medições de gases emanados do aquífero em poços de monitoramento, além da aplicação de métodos geofísicos.

Vários estudos geofísicos têm sido desenvolvidos envolvendo a contaminação do meio físico em subsuperfície por derivados de petróleo. $\mathrm{O}$ uso desta ferramenta em estudos ambientais é baseado em alterações nas propriedades físicas resultantes da presença de contaminantes no ambiente geológico, em grande parte detectáveis por meio do instrumental geofísico. As

\footnotetext{
${ }^{1}$ Universidade Estadual Paulista /UNESP. (acobraga@ rc.unesp.br e moreirac@rc.unesp.br)
} 
propriedades elétricas de solos e rochas são fortemente alteradas em presença de contaminantes como gasolina, álcool e diesel, em estado puro ou não diluído.

Diversos trabalhos descrevem a aplicação da geofísica em estudos de detecção, caracterização e monitoramento de áreas contaminadas por compostos orgânicos, como a aplicação de métodos Elétricos e Eletromagnéticos (LIMA et al., 1995; BENSON et al.,. 1997; MOREIRA e DOURADO, 2007; MOREIRA et al., 2007; MOREIRA e BRAGA, 2009).

A utilização dos métodos geoelétricos, principalmente Eletrorresistividade, apresenta excelentes resultados na identificação da pluma de contaminação por gasolina e/ou óleo diesel, analisando inclusive a variação temporal desses vazamentos (SAUCK, 2000; BRAGA et al., 2008).

Esses estudos, de um modo geral, diagnosticaram que os valores da resistividade de diferentes materiais geológicos, aumentaram significativamente logo após a contaminação do meio pelo hidrocarboneto. Ao longo do tempo, devido aos processos de biodegradação, esses valores da resistividade tenderiam a se normalizar e até diminuírem em relação ao valor padrão sem contaminação.

Outro contaminante resultante desses vazamentos ainda pouco estudado é o álcool etílico hidratado combustível, bastante utilizado como combustível na frota de veículos em nosso país. A resposta deste tipo de contaminante em sedimentos é ainda pouco conhecida em termos de alguns parâmetros geoelétricos, e de suas reações temporais com tal contaminante. Portanto, este trabalho apresenta os resultados obtidos através da integração simultânea dos métodos geoelétricos da eletrorresistividade, polarização induzida (domínio do tempo) e potencial espontâneo - técnica de investiga- ção da perfilagem, estudando esse tipo de contaminante - álcool etílico hidratado, em modelo reduzido de campo (vazamento controlado), procurando analisar, em termos geoelétricos, a intensidade das plumas resultantes e seus comportamentos, procurando obter um melhor entendimento nesse tipo de estudo.

\section{Descrição do Experimento}

Os ensaios geofísicos foram desenvolvidos em um tanque de fibra de vidro, com as seguintes dimensões na parte útil: $2,34 \mathrm{~m}$ (comprimento) $\mathrm{x}$ $1,34 \mathrm{~m}$ (largura) x $0,47 \mathrm{~m}$ (altura), preenchido por areia de granulometria fina a média (Figura 1). Nesse tanque foi simulado vazamento do combustível álcool etílico hidratado.

Procurou-se simular uma porção não saturada e outra saturada, sendo o nível d'água (NA) mantido a uma profundidade média de $10,0 \mathrm{~cm}$. Para o controle da saturação no tanque, instalaram-se três poços de controle $(\mathrm{P})$, construídos com tubos de PVC, com $50,0 \mathrm{~cm}$ de comprimento e $6,0 \mathrm{~cm}$ de diâmetro. Pequenos furos na parte inferior permitiram a entrada de água no sistema. Procurando estabelecer uma mínima variação do NA, a recarga da zona saturada foi mantida através de um sistema de alimentação controlado (bóia de recarga) instalado no poço P-1, a partir do qual, uma torneira de alimentação permitia a distribuição de água para o tanque com a mesma vazão.

Foram instaladas ainda duas sondas (S) para o desenvolvimento da perfilagem elétrica.

A contaminação foi efetuada a partir do centro do tanque, simulando um vazamento pontual a partir da superfície do terreno. Sendo introduzido um total de 20 litros de álcool combustível.

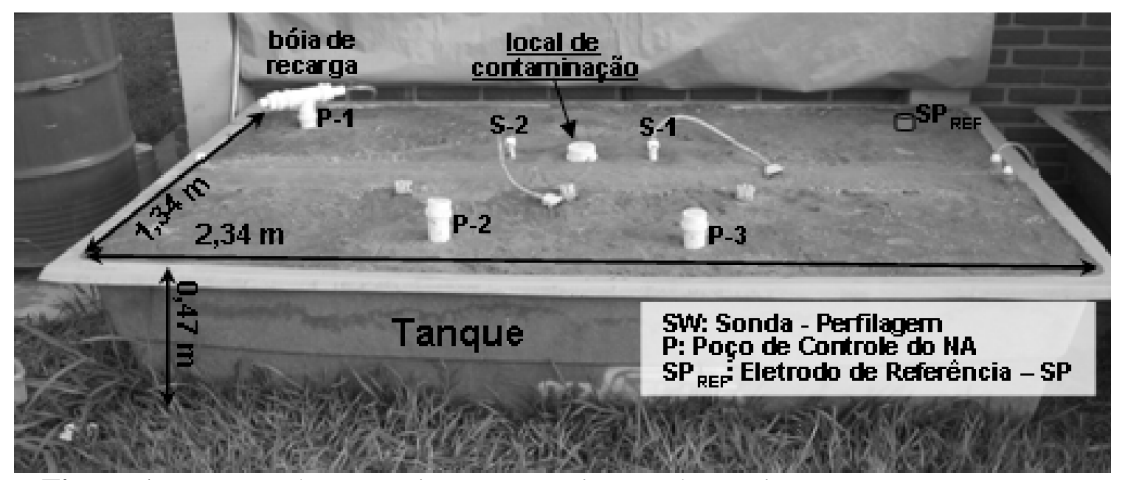

Figura 1 - Tanque de contaminação com sistema de monitoramento Figure 1 - Contamination tank with monitoring system 


\section{Técnica da Perfilagem Elétrica}

Esta técnica, cuja investigação normalmente se desenvolve no interior de furos de sondagem investigando os materiais geológicos in situ, foi desenvolvida a partir de duas sondas com 21 eletrodos de chumbo (Figura 2). Na execução dos métodos da eletrorresistividade e polarização induzida, o arranjo de desenvolvimento utilizado foi o dipolo-dipolo, com espaçamento $\mathrm{AM}=\mathrm{MN}=\mathrm{a}=$
4,0 cm, com deslocamento das leituras a cada 2,0 $\mathrm{cm}$, cujo ponto de atribuição da leitura é o local do eletrodo M. Para o método do potencial espontâneo, adotou-se o arranjo de base fixa, no qual o eletrodo de potencial $\mathrm{M}$ é colocado na superfície do tanque e o eletrodo $\mathrm{N}$ se desloca ao longo da sonda com espaçamento $=\mathrm{a}$, cujo ponto de atribuição da leitura é a posição do eletrodo N (Figura 3).

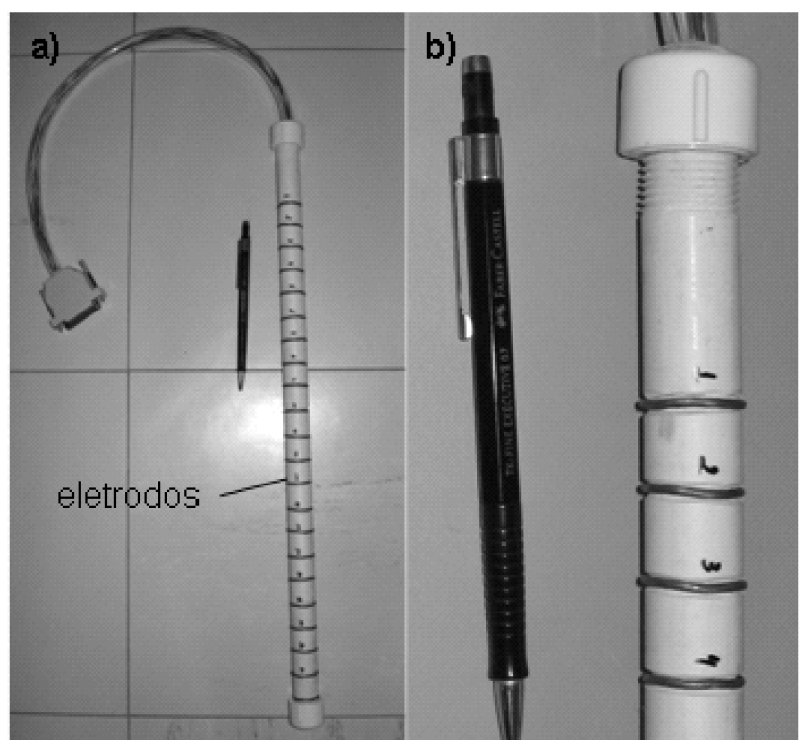

Figura 2 - a) Sonda utilizada na perfilagem elétrica. b) Em detalhe Figure 2-a) Probe used in electrical profiling. b) In detail
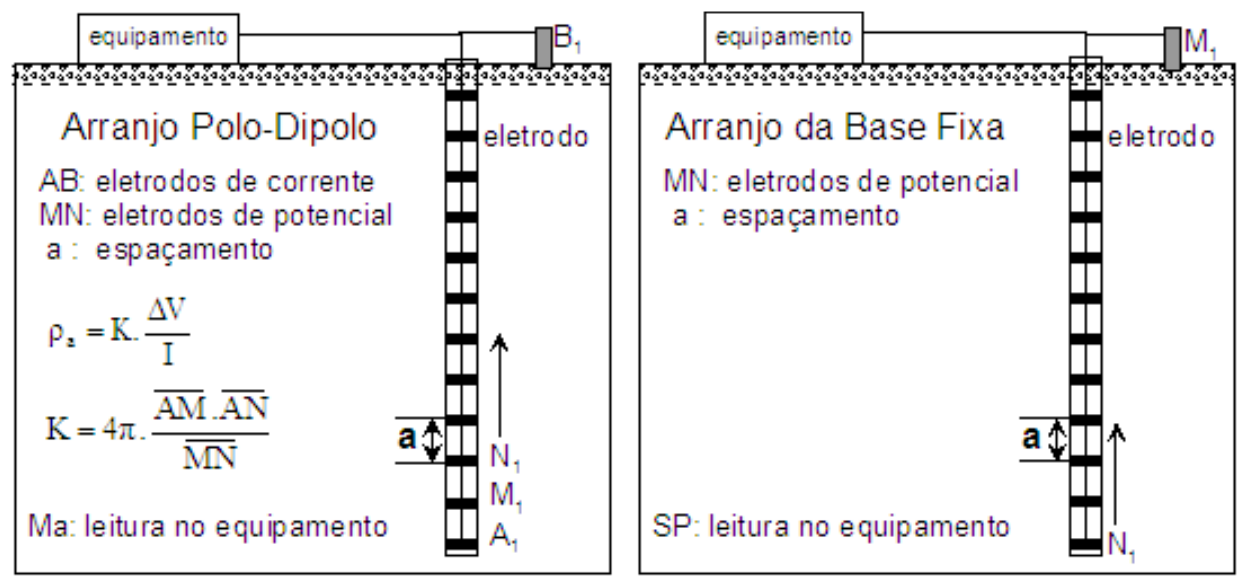

Figura 3 - Perfilagem elétrica - arranjos Pólo-Dipolo e Base Fixa

Figure 3 - Electrical profiling - Pole-Dipole and Fix Base arrays

\section{Equipamento e parâmetros medidos}

O equipamento utilizado foi $o$ resistivímetro Terrameter SAS 4000, fabricado pela ABEM (Suécia), com resolução de $1 \mu \mathrm{V}$. Este equipamento é calibrado para medidas de resistividade, cargabilidade e voltagem por meio de ciclos periódicos de corrente elétrica alternada e de baixa freqüência, procedimento que permite a filtragem de ruídos do sinal adquirido.

A razão V/I, ou seja, potencial (V) pela corrente (I) transmitida permite leituras diretas de resistência elétrica em ohm $(\Omega)$. A resistência medida é multiplicada pelo fator $\mathrm{K}$, que representa o espaçamento dos eletrodos em superfície e 
resulta no parâmetro resistividade aparente (equação 1):

$$
\rho=K \frac{\Delta \mathrm{V}}{\mathrm{I}} \quad \Omega . \mathrm{m} \text { (equação 1) }
$$

A polarização induzida é um fenômeno de geração de campo elétrico induzido pelo fluxo de corrente elétrica em subsolo de forma periódica e pulsante, observada como defasagem de voltagem em matérias terrestres (SUMNER, 1976). Os parâmetros de medidas de polarização induzida no domínio do tempo, procedimento de medida adotado neste trabalho, são determinados pela característica da forma da curva do potencial transiente, que podem ser a percentagem de polarização induzida, integral tempo-transiente e cargabilidade (TELFORD et al. 1990). A cargabilidade é definida pelo potencial transiente variável entre dois pontos da curva de decaimento transiente e normalizada pelo potencial primário, medido neste trabalho em termos de milissegundos (ms), é definido como (equação 2):

$$
M=\frac{1}{V_{c}} \int_{t 2}^{t 1} V_{t} d t
$$

ms (equação 2)

Foram utilizados $5 \mathrm{~mA}$ de corrente de transmissão, tempo de transmissão de corrente de $2 \mathrm{~s}$, leitura inicial em $0,01 \mathrm{~s}$ após o corte decorrente, janela única de leitura com 100ms e quatro de ciclos de aquisição.

O método de potencial espontâneo é caracterizado pela realização de leituras de campo elétrico natural, sem necessidade de quaisquer circuitos de injeção de corrente elétrica ou geração de campo eletromagnético (ORELLANA, 1972).

Sua vantagem reside na simplicidade no instrumental envolvido e versatilidade de aquisição de dados em pequenas áreas, além da variabilidade do parâmetro físico quando medido no ambiente geológico.

As principais desvantagens associadas ao método são a necessidade de cabos de conexão entre os sensores de leitura e o equipamento, uso de eletrodos não polarizáveis, além da elevada susceptibilidade a ruídos produzidos por sistemas elétricos como transformadores, aterramentos e motores, elementos que podem inviabilizar ensaios em grandes áreas ou em ambiente urbano.

\section{Apresentação dos resultados}

As medidas de resistividade elétrica, cargabilidade e potencial elétrico natural são apresentadas em gráficos (Figuras 4 a 6).

Inicialmente foram realizadas medidas dos parâmetros físicos antes do vazamento de álcool etílico hidratado combustível no tanque, que correspondem ao tempo 0hs nos gráficos. As medidas de resistividade foram de $265 \Omega$.m para a zona não saturada e $142 \Omega$.m para a zona saturada. As medidas de cargabilidade foram de $3,2 \mathrm{~ms}$ para a zona não saturada e1,92ms para a zona saturada. Os valores de voltagem foram de $59 \mathrm{mV}$ para a zona não saturada e $22 \mathrm{mV}$ para a zona saturada.

Os dados de resistividade elétrica apresentam um padrão de variação relativamente semelhante entre zona saturada e zona não saturada. Em termos gerais, ocorre aumento nos valores após o início do experimento, seguido por queda acentuada e sucedido por crescimento lento e constante dos valores (Figura 4).

As medidas relativas á zona não saturada apresentam amplo contraste nos termos iniciais, com pico de resistividade de $807 \Omega$.m após 24hs, seguido por queda brusca o valor mínimo de $65 \Omega$.m após $216 \mathrm{hs}$. A curva de resistividade para a zona saturada apresenta um pico de $166 \Omega$.m após $24 \mathrm{hs}$, sucedido por queda acentuada até o valor mínimo de $65 \Omega$.m após $504 \mathrm{Hs}$.

As medidas de profundidade do nível freático descrevem certa oscilação, com valores que variam entre $6 \mathrm{~cm}$ e $18 \mathrm{~cm}$, sem, contudo, aparentemente exercer influência nos valores de resistividade.

Os dados de cargabilidade também apresentam um padrão de variação relativamente semelhante entre zona não saturada e zona saturada. Há um aumento inicial nos valores, queda sucedida com novo aumento, queda brusca seguida por queda suave e contínua (Figura 5). 


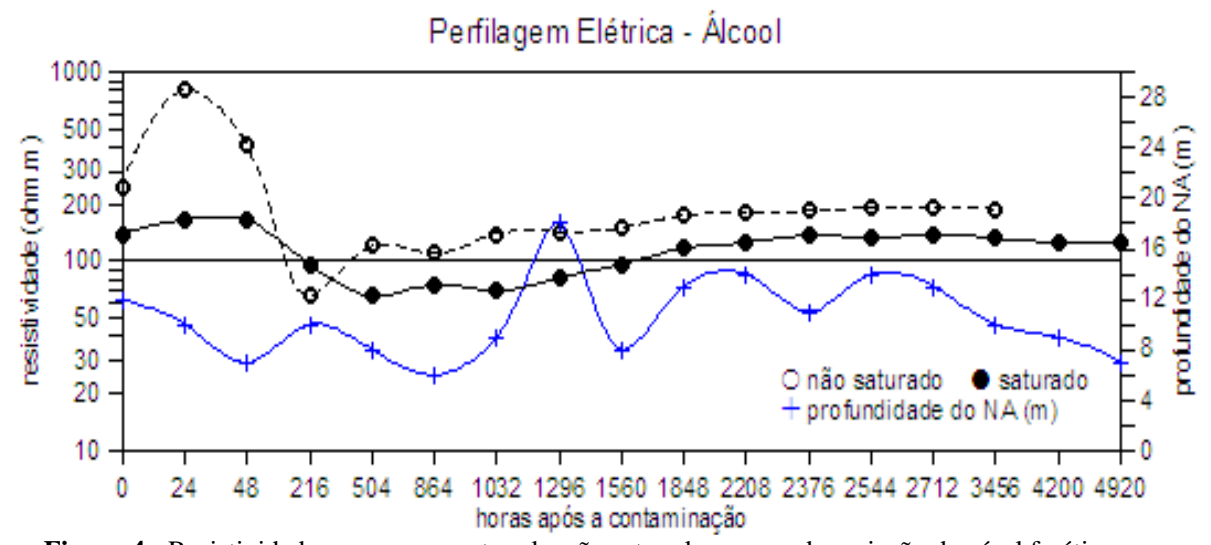

Figura 4 - Resistividade para a zona saturada, não saturada e curva de variação do nível freático

Figure 4 - Resistivity for saturated zone, non saturated and variation curve of the groundwater level

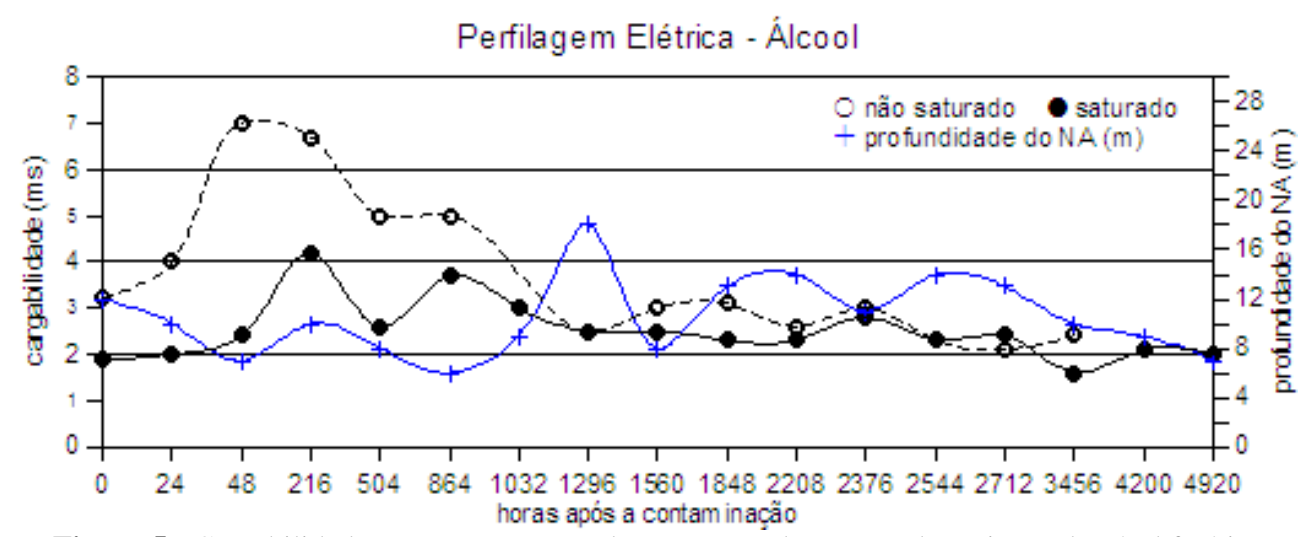

Figura 5 - Cargabilidade para a zona saturada, não saturada e curva de variação do nível freático

Figure 5 - Chargeability for saturated zone, non saturated and variation curve of the groundwater level

As medidas relativas à zona não saturada apresentam um contraste acentuado nos termos iniciais, com pico de cargabilidade de $7 \mathrm{~ms}$ após $48 \mathrm{hs}$, seguido por queda acentuada para $5 \mathrm{~ms}$ após $504 \mathrm{hs}$ sucedida por leve aumento e nova queda para 3,3ms após $1296 \mathrm{hs}$, a partir da qual ocorrem pequenas oscilações e tendência de queda nos valores.

A curva para a zona saturada apresenta um contraste relativamente menor, com pico de cargabilidade de $4,1 \mathrm{~ms}$ após $216 \mathrm{hs}$, sucedido por queda brusca para 2,3ms após 504hs, seguido por aumento e nova queda pouco acentuada para 2,2ms após $1296 \mathrm{~ms}$, a partir do qual a partir do qual ocorre pequenas oscilações e tendência de queda nos valores.

As variações de profundidade do nível freático aparentemente exercem influência nos valores de cargabilidade, pois diversos pontos de subida ou descida do nível freático acompanhada por tendências semelhantes de oscilação das medidas de cargabilidade, tanto para a zona não saturada quanto para a zona saturada.

Em contraste com dos demais, os dados de potencial espontâneo são variáveis e não permitem o estabelecimento de tendências (Figura 6). As medidas referentes à zona não saturada são, em média, três vezes maiores em relação às medidas obtidas para a zona saturada. Sob este aspecto de variações, as curvas para ambas as zonas variam de forma idêntica. O padrão de variação do nível freático também é bastante semelhante ao descrito para ambas as zonas, mas principalmente para a zona saturada. 


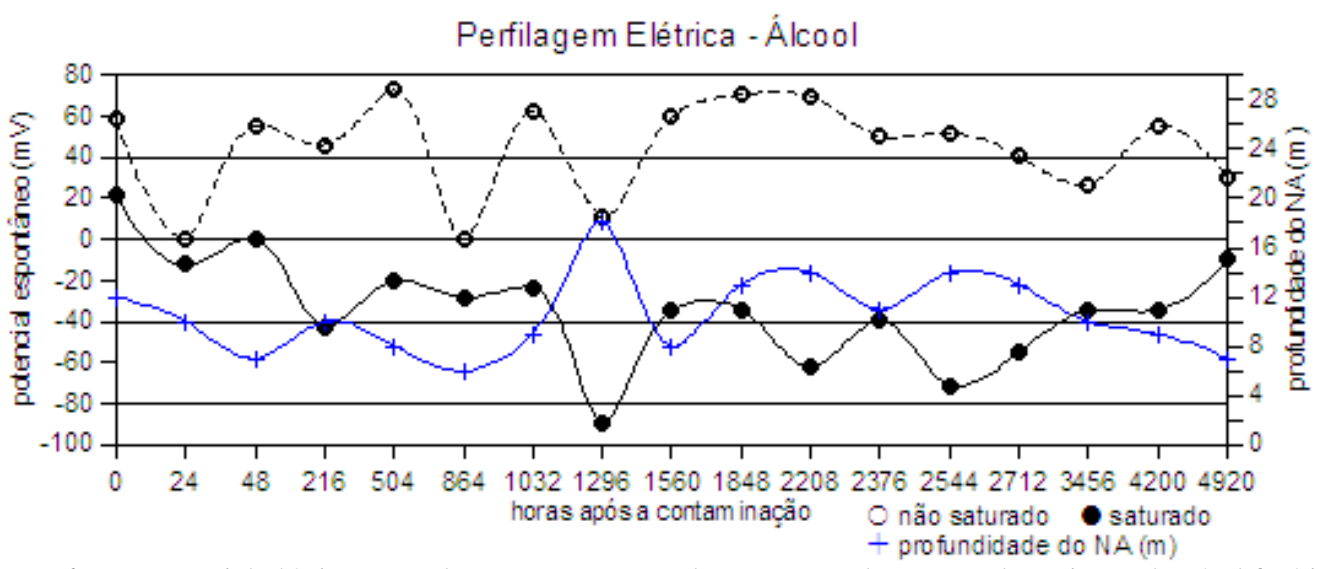

Figura 6 - Potencial elétrico natural para a zona saturada, não saturada e curva de variação do nível freático

Figure 6 - Natural electric potential for saturated zone, non saturated and variation curve of the groundwater level

\section{Discussão dos Resultados}

A degradação aeróbica dos contaminantes eventualmente presentes em subsolo depende da disponibilidade de oxigênio, que, por sua vez, é condicionada à difusão através da zona não saturada em fluxo vertical e pelo transporte por movimentação das águas subterrâneas em fluxo horizontal. Neste sentido, uma das hipóteses aventadas para compreensão das variações descritas nos parâmetros físicos medidos ao longo do experimento, são alterações no álcool etílico hidratado combustível sob processos de biogradação.

A biodegradação de etanol consiste numa reação de oxidação/redução realizada durante o processo respiratório microbiano. Durante a oxidação do composto ocorre doação de elétrons para os microorganismos, ou seja, uma reação de oxidação com o objetivo de obtenção de energia para o metabolismo microbiano produção e manutenção celular (GRADY at el., 1999).

Doadores de elétrons podem ser compostos orgânicos diversos, dentre os quais está o etanol. Este processo ocorre primordialmente durante processos de degradação, onde o oxigênio atua como receptor de elétrons e o composto orgânico como doador de elétrons (BELLER et al.,1992; GRBIC-GALIC e VOGEL, 1987).

A reação de biodegradação aeróbica do etanol necessita de grandes quantidades de oxigênio, a ponto de em muitos casos transformar um ambiente inicialmente aeróbico num ambiente anaeróbico.

No caso do ambiente criado para o desenvolvimento do projeto que envolveu a contamina ção por etanol e medidas geofísicas, a perda de água por evaporação foi continuamente reposta por um sistema de estabilização do nível freático. Desta forma, a recarga constante de água pressupõe uma reposição contínua do oxigênio no sistema, que colabora para a predominância de condições aeróbicas durante a aquisição de dados geofísicos (POWERS et al., 2001; MARTINS, 2004) (Equação 1).

$$
\mathrm{CH}_{3} \mathrm{CH}_{2} \mathrm{OH}+\mathrm{O}_{2} \rightarrow \mathrm{CH}_{3} \mathrm{COOH}+\mathrm{H}_{2} \mathrm{O} \rightarrow \underset{\text { (Equação 1) }}{\mathrm{CH}_{4}+\mathrm{CO}_{2}}
$$

Embora tenha havido reposição constante da água subterrânea, no nível freático o oxigênio é obtido pela decomposição da molécula da água. Bactérias anaeróbicas frequentemente decompõem o etanol em $\mathrm{CO}_{2}$ e $\mathrm{H}_{2} \mathrm{O}$, num processo que envolve inicialmente a oxidação do etanol em acetaldeído, posterior conversão em acetil-CoA ou em acetato (Equação 2). O acetato é convertido em acetil-CoA posteriormente. $\mathrm{O}$ acetil-CoA é oxidado em $\mathrm{CO}_{2}$ no Ciclo de Krebs (POWERS et al., 2001; MARTINS, 2004).

$$
\begin{aligned}
& \mathrm{CH}_{3} \mathrm{CH}_{2} \mathrm{OH}+2 \mathrm{H}_{2} \mathrm{O} \rightarrow \mathrm{CH}_{3} \mathrm{COO}-+\mathrm{H}_{2} \mathrm{O}+4 \mathrm{H}_{2} \rightarrow \mathrm{CH}_{4}+\mathrm{CO}_{2} \\
& \text { (Equação 2) }
\end{aligned}
$$

Desta forma, a interpretação dos dados pode ser realizada preliminarmente de forma distinta entre zona saturada e não saturada.

A tendência de variação de resistividade para a zona não saturada pode estar associada ao 
comportamento geoquímico do etanol no ambientegeológico. O aumento de resistividade inicial está associado à percolação de etanol neste intervalo, que provavelmente atinge o grau máximo de saturação após 24hs do início do experimento.

A queda na curva pode estar associada ao estabelecimento da fase de oxidação do etanol e sua conversão em acetaldeído e água, com a máxima geração deste último composto após $216 \mathrm{hs.} \mathrm{O}$ crescimento gradativo e constante da curva de resistividade após este período pode descrever a fase final de oxidação do etanol, ou seja, transformação do acetaldeído em gás carbônico e metano (Equação 1).

Esta análise também é válida para a zona saturada, dada a semelhança das curvas de resistividade. Contudo, a oxigênio necessário para desenvolvimento das reações é obtido pela dissociação da molécula da água, algo relativamente mais lento quando comparado ao ambiente aeróbico (Equação 2).

Deste sentido, o ponto de menor resistividade para a zona saturada ocorre após 504hs, ou seja, mais que o dobro do período requerido pela zona não saturada. Seus valores são quase sempre mais reduzidos que as medidas para a zona não saturada, devido à condição de baixa resistividade estabelecida pela presença de água neste ambiente, mesmo antes do vazamento de álcool etílico hidratado combustível.

A curva de cargabilidade para a zona não saturada apresenta seu pico de valores numa fase onde há uma queda na resistividade. É provável que o aumento crescente na presença de acetaldeído seja responsável pelo aumento na polarizibilidade deste ambiente.

A defasagem de tempo entre o pico de cargabilidade para a zona não saturada (após 48hs) e o pico para a zona saturada (216hs) indica que o processo de dissociação da molécula da água para obtenção de oxigênio também é pertinente e influencia este parâmetro físico, a ponto de ser necessário um período de tempo quatro vezes maior para que haja um aumento substancial de cargabilidade para a zona saturada.

A relação direta entre oscilação do nível freático e variação direta principalmente nos valores de potencial espontâneo para a zona saturada é uma clara evidência da disponibilidade de oxigênio Águas Subterrâneas (2012) 26(1): 19-26. e alterações no potencial elétrico natural. $\mathrm{O}$ trabalho de Timm e Möller (2001) descreve que o potencial espontâneo é uma medida que envolve a soma do potencial de oxidação/redução e o potencial de fluxo.

O potencial de fluxo deve exercer pequena influência nas medidas neste experimento, devido a posição horizontal do tanque e a lenta reposição do nível freático perdido por evapotranspiração. Desta forma, as medidas de potencial elétrico natural na prática refletem as condições de oxidação e redução do ambiente, que, por sua vez, dependem da atividade do íon oxigênio.

Neste sentido, a associação entre aumento de cargabilidade e subida do nível freático indica o potencial de oxidação/redução exerce influência neste parâmetro físico. $\mathrm{O}$ aumento no teor de oxigênio está implícito na subida do nível freático, que resulta na maior disponibilidade de elétrons $\left(\mathrm{O}^{-}\right)$e consequente aumento do potencial de polarizibilidade do ambiente contaminado.

\section{CONCLUSÕES}

Este trabalho demonstra a importância de estudos geofísicos que versam a avaliação do comportamento de parâmetros físicos em ambientes que simulem contaminações do meio geológico.

A análise temporal revela claramente que os parâmetros físicos resistividade elétrica, cargabilidade e potencial elétrico natural são variáveis e que este fenômeno deve resultar de processos de alteração fisico-química do etanol.

O potencial elétrico natural revelou sua associação direta com a disponibilidade de oxigênio do ambiente, ou seja, alteração no potencial de oxidação/redução associado a oscilações do nível freático. Os dados indicam que a interpretação do parâmetro cargabilidade é algo de maior complexidade, pois sua variação está associada tanto às fases de conversão de etanol quanto a disponibilidade de oxigênio. Contudo, os resultados demonstram sua eficiência em estudos de áreas contaminadas.

Neste aspecto, a aplicação do método de Polarização Induzida em estudos de contaminação deve pressupor um conhecimento amplo do tipo de composto presente no ambiente e seu comportamento geoquímico temporal, algo que em diversos casos torna seu uso limitado devido á indisponibi- 
lidade de informações preliminares em diversos estudos ambientais.

O custo relativamente elevado do equipamento em relação aos resistivímetros convencionais, aliado á necessidade de eletrodos não polarizáveis e a maior susceptibilidade a ruídos em áreas urbanas, são fatores negativos de sua aplicação em estudos ambientais.

Há uma relação direta entre as fases suces- sivas de conversão do etanol em gás carbônico e me- tano e variações de resistividade elétrica. As oscilações do nível freático não exerceram influência nos valores medidos e a definição clara de padrões de variação associados ás fases de decomposição do etanol no ambiente geológico demonstram que o método da eletrorresistividade é altamente recomendável em estudos de caracterização e monitoramento de áreas contaminadas por etanol.

\section{AGRADECIMENTOS}

Este trabalho foi realizado com apoio financeiro da Fundação de Amparo a Pesquisa do Estado de São Paulo (FAPESP), a partir do projeto de pesquisa intitulado "Métodos Geoelétricos aplicados em estudos de contaminação de sedimentos por Combustíveis”, processo n. 2007/04517-7.

\section{REFERÊNCIAS}

BELLER, H. R.; GRBIC-GALIC, D; REINHARD, M. Microbial degradation of toluene under sulfate-reducing conditons and influence of iron on the processes. Applied and Environmental Microbiology, v. 58, n.3, p.786-793, 1992.

BENSON, A.K.; PAYNE, K.L.; STUBBEN, M.A. Mapping groundwater contamination using dc resistivity and VLF geophysical methods: a case study. Geophysics, v. 62, n. 1, p. 80-86, 1997.

BRAGA, A. C. O.; MOREIRA, C. A.; CARDINALLI, M. T. Variação temporal da resistividade elétrica em contaminação por gasolina. Geociências, v. 27, n.4, p.517-525, 2008. Disponível em

<http://www.periodicos.rc.biblioteca.unesp.br/index.php/geoci encias/article/view/3418/2862>. Acesso em: 06 nov. 2011.

EPA - United States Environmental Protection Agency. Use of monitored natural attenuation at superfund, RCRA corrective action, and underground storage tank sites. Office of Solid Waste and Emergency Response, Directive 9200. p.417, 1999. Disponível em: 〈http://www.epa.gov>. Acesso em: 06 nov. 2011.

GRADY, C. P. L.; DAIGGER, G. T.; LIM, H. Biological wastewater treatment. 2. Ed. New York: Marcel Dekker, 1999. $1096 \mathrm{p}$.

GRBIC-GALIC, D. \& VOGEL, T. M. Transformation of toluene and benzene by mixed methanogenic cultures. applied and environmental microbiology. American Society for Microbiology, v. 53, n. 2, p. 254-260, 1987.

LIMA, O.A.L.; SATO, H.K.; PORSANI, M. J. Imaging industrial contaminant plumes with resistivity techniques. Journal Applied Geophysics, v. 34, n. 2, p. 93-108, 1995.

MARTINS, B. A. D. Avaliação da cinética de biodegradação do Etanol em concentrações mínimas necessárias dos nutrientes nitrogênio e fósforo., 96f. Dissertação (Mestrado em Eng. Ambiental), UFSC. Florianópolis, 2004. Disponível em: 〈http://www.tede.ufsc.br/teses/PGEA0184.pdf〉. Acesso em: 06 nov. 2011.
MOREIRA, C. A \& DOURADO, J. C. Monitoramento da atenuação natural de pluma de contaminação pelo método de Radar de Penetração no Solo (GPR). Revista Brasileira de Geofísica, v. 25, n.4, p. 389-398, 2007. Disponível em: $<$ http://www.scielo.br/pdf/rbg/v25n4/a03v25n4.pdf >. Acesso em: 06 nov. 2011.

MOREIRA, C. A.; AQUINO, W. F.; DOURADO, J. C. Aplicação do método eletromagnético indutivo (EM) no monitoramento de contaminantes em subsuperfície. Revista Brasileira de Geofísica, v. 25, n.4, p. 413-420, 2007. Disponível em: $<$ http://www.scielo.br/pdf/rbg/v25n4/a05v25n4.pdf $>$. Acesso em: 06 nov. 2011.

MOREIRA, C. A. \& BRAGA, A. C. O. Aplicação de métodos geofísicos no monitoramento de área contaminada sob Atenuação Natural. Revista de Engenharia Sanitária e Ambiental, v. $14, \quad$ n.2, p.257-264, 2009. Disponível em: <http://www.scielo.br/pdf/esa/v14n2/a13v14n2.pdf>. Acesso em: 06 nov. 2011.

ORELlANA, E. Prospeccion geoelectrica en corriente continua, Madrid: Paraninfo, 1972. 523 p.

POWERS, S. E.; HUNT, C. S; HEERMANN, S. E.; CORSEUIL, H. X.; RICE, D. ALVAREZ, J. J. The transport an fate of ethanol and BTEX in groundwater contaminated by gasohol. CRC Environmental Science and Technology, v. 31, n.1, p. 79-123, 2001.

SAUCK, W. A. A model for the resistivity structure of LNAPL plumes and their environments in sandy sediments. Applied Geophysics, n.44, p. 151-165, 2000.

SUMNER, J.S. Principles of induced polarization for geophysical exploration. Amsterdam: Elsevier, 1978. 277 p.

TELFORD, W. M.; GELDART, L. P.; SHERIFF, R. E. Applied geophysics. 2. ed. NY: C.University Press, 1990. 774 p.

TIMM, \& MÖLLER, The relation between electric and redox potential: evidence from laboratory and field measurements. Journal of Geochemical Expl., v. 27, n.2, p.115-128, 2001. 